\title{
Recursos educacionais e abertura: Percepções e práticas docentes no ensino superior
}

\section{Tel Amiel ${ }^{1}$, Robson Mesquita ${ }^{1}$, Andre Oddone ${ }^{1}$, Maria Esther Alexandre ${ }^{1}$, Gabriela Miguel $^{1}$, Maria de Fátima dos Santos Figueirôa ${ }^{1}$}

\author{
Faculdade de Educação - Universidade de Brasília (UnB) \\ Campus Darcy Ribeiro - Brasília - DF - Brasil \\ \{amiel@unb.br,robsoncruz.dacruz88@gmail.com, andre oddone@hotmail.com, \\ esthercostax@gmail.com, gabriela.cmiguel@gmail.com, \\ lindaenic@gmail.com\}
}

\begin{abstract}
This article presents the result of a research project aimed at understanding the perceptions and practices of professors in regards to educational resources used in their classes. The study was conducted at a School of Education and aimed to understand how those who teach our future teachers search for, produce, and make available their educational resources, and how this relates to Open Educational Resources and Practices $(O E R / O E P)$. The results indicate that professors make extensive use of the digital space to find and make resources available, and weariness in regards to the use and reuse of resources from third parties. We discuss these and other results and how they can be used for professional development in the field of open education.
\end{abstract}

Resumo. Este artigo apresenta o resultado de um levantamento sobre práticas e percepções de docentes quanto aos recursos educacionais que utilizam em suas disciplinas. O estudo, conduzido em uma Faculdade de Educação, visou compreender como os formadores de professores buscam, produzem $e$ disponibilizam seus recursos educacionais, e suas relações com Práticas $e$ Recursos Educacionais Abertos (PEA/REA). Os resultados apontam que docentes fazem uso do espaço digital para encontrar e disponibilizar recursos educacionais, no entanto, apontam receios quanto ao uso e reuso de recursos de terceiros. Discutimos como esses e outros resultados podem levar a oportunidades de formação no âmbito da educação aberta.

\section{Introdução}

Os Recursos Educacionais Abertos (REA) são materiais de estudo, ensino e aprendizagem que podem ser acessados e utilizados por qualquer um que deseje, visando uma democratização e facilitação do acesso e da utilização de obras educacionais. Potencializa que os indivíduos criem, compartilhem e editem esses materiais com liberdade. Podem existir na forma de livros, artigos, documentos, vídeos, imagens, software livre, aplicativos e até mesmo jogos, por exemplo.

Pereira, Fettermann e César (2014, p. 465), propõe que os Recursos Educacionais Abertos podem ser formalmente definidos como:

[...] REA são materiais educacionais multiformes, com potencialidades para os multiletramentos e para os processos de ensino e de aprendizagem em 
VIII Congresso Brasileiro de Informática na Educação (CBIE 2019)

Anais do XXV Workshop de Informática na Escola (WIE 2019)

espaços formais (em todos os níveis de ensino) e não formais, nas diversas áreas de conhecimento e em práticas interdisciplinares, tendo uma licença que garanta seu uso, aprimoramento, recombinação e distribuição.

Os REA não são um campo de conhecimento e de prática isolado; dialogam com competências relacionadas as tecnologias da comunicação e informação, e buscam promover uma nova ética de trabalho (mais aberta) no âmbito da cultura digital elementos de reconhecida importância em normativas oficiais com o Plano Nacional de Educação e a Base Nacional Comum Curricular (Amiel, Gonsales, \& Sebriam, 2018). Nesse sentido, dialoga também com outros movimentos, como o software livre, o acesso aberto ao conhecimento científico, o hardware livre, dentre outros.

Os REA podem contribuir para o desenvolvimento educacional de diversas formas. Esses incluem facilitar acesso a recursos para estudantes que têm dificuldade para acessar fontes de estudo de qualidade, por não poderem comprar ou pagar pelo acesso (Rodés, Casas, Ochoa, \& da Silveira, 2012); professores que estão em busca de novas práticas e materiais de ensino; ou ainda, pesquisadores cuja área de atuação tenha pouco material didático relacionado produzido e disponível (Craveiro, Machado, \& Ortellado, 2008). Os REA e práticas associadas também podem fomentar uma cultura de compartilhamento e valorização da produção cultural existente, partindo do reconhecimento que trabalhar a partir de produção de outrem pode contribuir para o seu desenvolvimento profissional, pessoal e acadêmico.

Ainda há uso limitado dos REA pela comunidade acadêmica e a sociedade como um todo, muitas vezes devido ao desconhecimento ou a hábitos de apego a noções de posse e individualismo, contrárias ao compartilhamento de informações. Apesar de um crescente número de estudo sobre o tema, há ainda no cenário brasileiro uma quantidade limitada de estudos que nos permitam melhor entender o nível de adesão e as percepções de docentes sobre os REA (Amiel \& Duran, 2015; de Almeida Pereira \& Alves, 2015; Mallmann, Jacques, Mazzardo, Bagetti, \& Lauermann, 2018; Mazzardo, Nobre, \& Mallmann, 2016b; Thiago Soares \& Amiel, 2018).

Nessa pesquisa buscamos contribuir e expandir as pesquisas sobre a percepção e prática de docentes com REA. Adicionamos a essa preocupação o uso da pesquisa como um elemento para diagnosticar e servir como base para proposição de oficinas de formação aos docentes.

\section{REA no Brasil}

Apesar de ainda incipiente, é crescente a discussão sobre os REA no Brasil (Zancanaro \& Amiel, 2017). Por exemplo, Bagetti, Mussoi e Mallmann (2017) realizaram uma pesquisa-ação com 22 docentes em formação avaliando sua fluência tecnológica e pedagógica com enfoque em REA. A pesquisa também serviu como momento de formação com os alunos de licenciatura, abordando conceitos como coautoria e o uso de licença Creative Commons, experienciados pelos alunos através de oficinas práticas e produção de vídeo. Já Mazzardo, Nobre, Mallmann (2016a) levantaram informações com professores de ensino médio acerca de seus conhecimentos e interesses sobre REA. Com base nesses dados, foi criado um guia sobre REA para docentes.

Políticas públicas também tem ajuda a impulsionar o interesse sobre o tema. Podemos destacar a recente Portaria do Ministério da Educação (415/2018), que define no seu $7^{\circ}$ artigo que: “(...) deverão ser sempre abertos os recursos educacionais ou 
VIII Congresso Brasileiro de Informática na Educação (CBIE 2019)

Anais do XXV Workshop de Informática na Escola (WIE 2019)

produzidos com fundos públicos”. No distrito federal, por exemplo, há uma lei (5.592/2015) que determina o uso de licenças livres para recursos educacionais:

“...institui uma política de disponibilização aberta de recursos educacionais comprados ou desenvolvidos por subvenção da administração direta e indireta, garantindo que sejam disponibilizados na internet e licenciados para livre utilização, compreendendo a cópia, a distribuição, o download e a redistribuição, desde que preservados o direito de atribuição ao autor e uso para fins não comerciais”.

A existência de legislação é somente um passo para a efetiva adoção dos REA. É necessário fomentar o interesse e conhecimento sobre o universo do ‘aberto' ainda na formação docente. Para tal, é necessário melhor conhecer as perspectivas dos formadores de docentes em nossas instituições de ensino superior.

\section{Metodologia}

Este trabalho se desenvolveu através da aplicação de um questionário, desenvolvido com base em (Tiago Soares \& Amiel, 2017), para avaliar percepções e práticas docentes com recursos educacionais e recursos educacionais abertos. Dada a similaridade do contexto do trabalho original, mas reconhecendo as especificidades desse público, itens foram analisados individualmente e removidos para que pudessem se adequar ao público em questão e reduzir o tempo de engajamento para aproximadamente 15 minutos. O questionário buscou levantar dados através de uma autoavaliação de percepções e comportamentos nas seguintes áreas:

1. Competências instrumentais (escala de competências)

2. Tipos de recursos que professores pedem que alunos façam uso

3. Onde recursos são disponibilizados por docentes

4. Onde docentes buscam por recursos educacionais

5. Práticas de produção e reuso por parte dos docentes

6. Prioridades (fatores) que se relacionam com a escolha de recursos educacionais

7. Barreiras para a escolha de recursos educacionais

Os dados foram coletados prioritariamente de forma presencial durante um semestre. No entanto, alguns docentes preferiam levar o questionário para casa e devolvê-los com as respostas de forma impressa. Em um segundo momento, visando aumentar a adesão o questionário foi colocado online para permitir maior resposta dos participantes. Um total de 40 respondentes de um universo aproximado de 85 docentes respondeu ao questionário.

O questionário faz uso de uma escala Likert com valores que vão de 1 a 5 . Apresentamos abaixo os dados descritivos em gráficos apresentando o número de respondentes $(\mathrm{N})$ e a média. Em se tratando de uma escala ordinal, apresentamos os dados indicando o número de respondentes por resposta (de 1 a 5). Como os dados são descritivos e análises de inferência não foram executadas, as médias computadas ignoram o caso onde não houve resposta, ou seja, os dados sem resposta não foram substituídos por outros valores. 
VIII Congresso Brasileiro de Informática na Educação (CBIE 2019)

Anais do XXV Workshop de Informática na Escola (WIE 2019)

\section{Resultados}

Perguntamos aos docentes como avaliariam sua habilidade para ensinar alguém (Figura 1) a completar uma série de atividades de ordem técnica (1 sendo pouco hábil e 5 sendo muito hábil). O uso do ensinar alguém aumenta o nível de complexidade da tarefa, dado que buscamos avaliar até que ponto o docente considera sua competência alta o suficiente para não somente usar, mas ensinar a alguém.

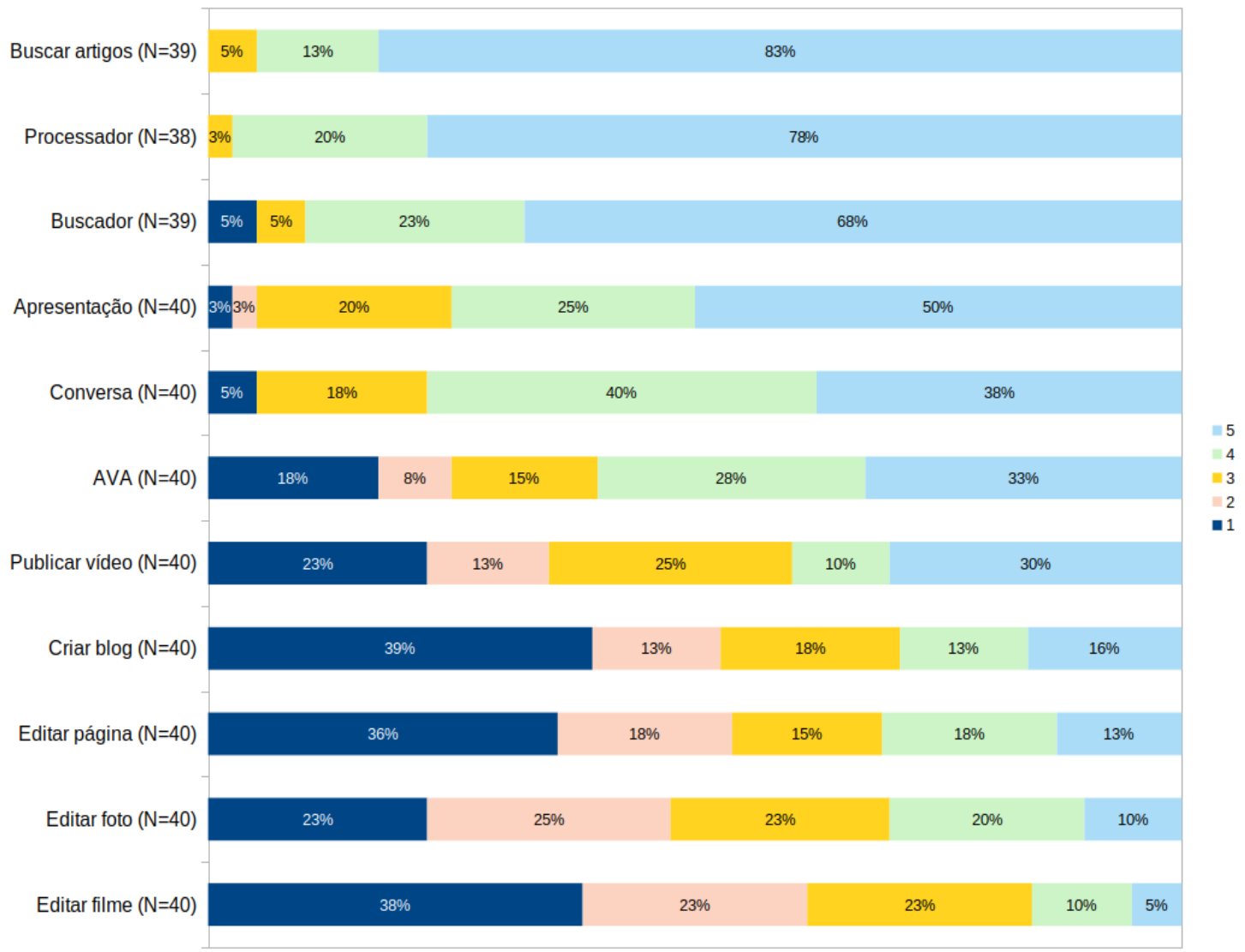

Figura 1. Habilidade para ensinar a alguém no uso das TICs ( 1 = pouca e 5 = muita)

Essas habilidades podem ser importantes para medir a capacidade do docente para engajar na produção, uso e reuso de recursos educacionais, particularmente considerando que o reuso e o remix são atividades de grande importância nas práticas relacionadas aos REA.

Percebemos que atividades como a busca por artigos e o uso de um buscador (geral), bem como o uso de software de produtividades (processadores de texto e apresentações) são os elementos destacados como sendo os de maior fluência. Atividades tidas como mais complexas e relacionadas à cultura digital, como a produção de um blog, a edição de vídeos, fotos e páginas online (como uma página numa wiki) são avaliadas como sendo mais complexas.

Quando perguntados sobre os recursos educacionais utilizados em aula (Figura 2), os docentes responderam qual era o seu grau de preferência para sete formas de disponibilizar os “artigos, livros e capítulos de livros” impressos e digitais, além de uma opção aberta relacionada a "outro tipos de recursos educacionais disponíveis na internet” no âmbito de suas disciplinas. 
VIII Congresso Brasileiro de Informática na Educação (CBIE 2019)

Anais do XXV Workshop de Informática na Escola (WIE 2019)

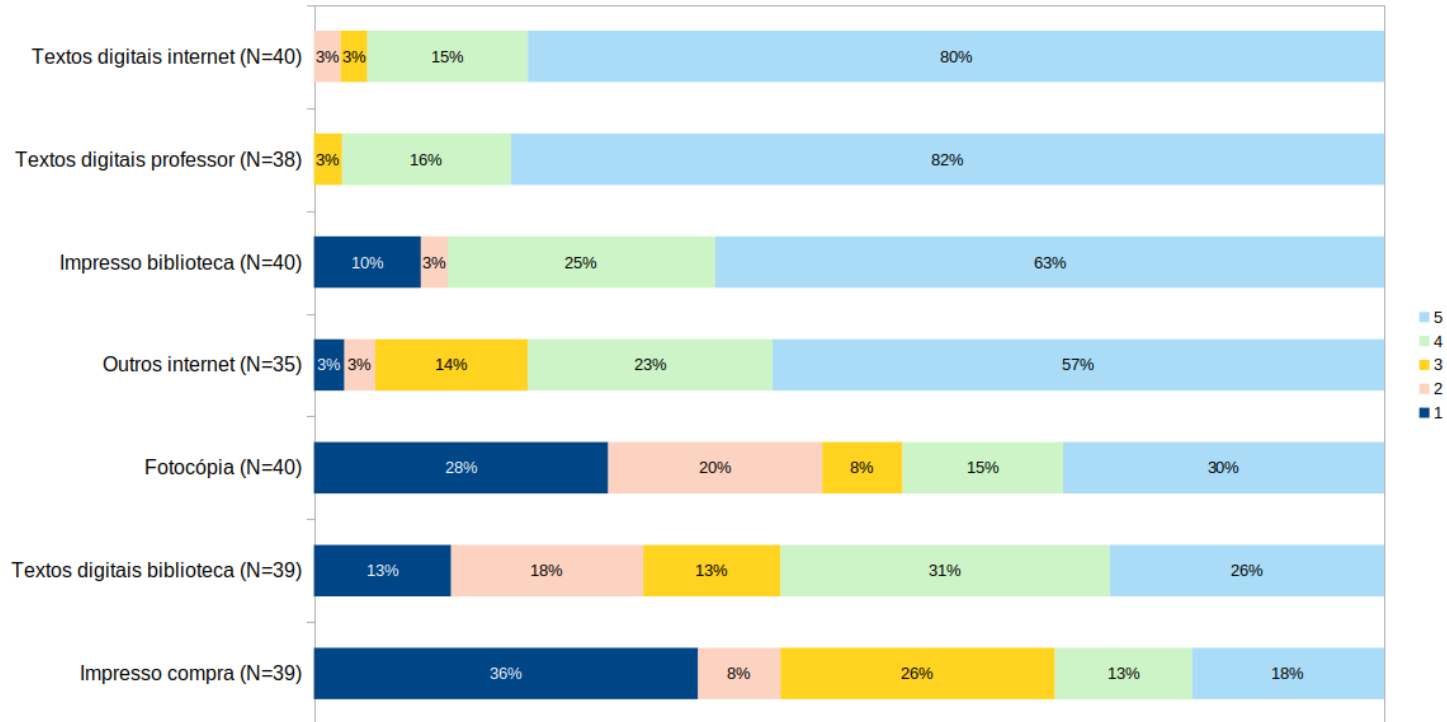

Figura 2. Tipos de recursos educacionais utilizados nas disciplinas $(1$ = nunca e 5 = sempre)

As formas digitais têm grande adesão, na forma de livros e outros materiais textuais disponíveis na internet (Figura 2). A forma menos preferível pelos entrevistados foi a impressa, para compra. A fotocópia, mesmo sendo uma forma impressa e paga, obteve avaliações de frequência de semelhante proporção. Isso é explicado pelo contexto, dado que a prática de disponibilizar recursos para cópia no "xerox" é consolidada nesse ambiente. Portanto, a tradição que essa copiadora tem dentro da Faculdade influencia os professores a disponibilizar os seus materiais por lá, mesmo que eles aparentemente deem preferência aos formatos digitais e gratuitos. Importante ainda ressaltar que a opção por "outros” tipos de recursos disponíveis na internet apresentou volume substancial (57\% respondendo "sempre”).

Questionamos os docentes acerca do local onde disponibilizam os recursos educacionais digitais utilizados em suas disciplinas. Buscamos um levantamento a prática dos docentes com relação a distribuição dos recursos, bem como a receptividade dos professores ao uso de plataformas e/ou sites abertos. Percebemos (Figura 3) que os docentes têm preferência em disponibilizar recursos em sites externos (como Dropbox, Slideshare).

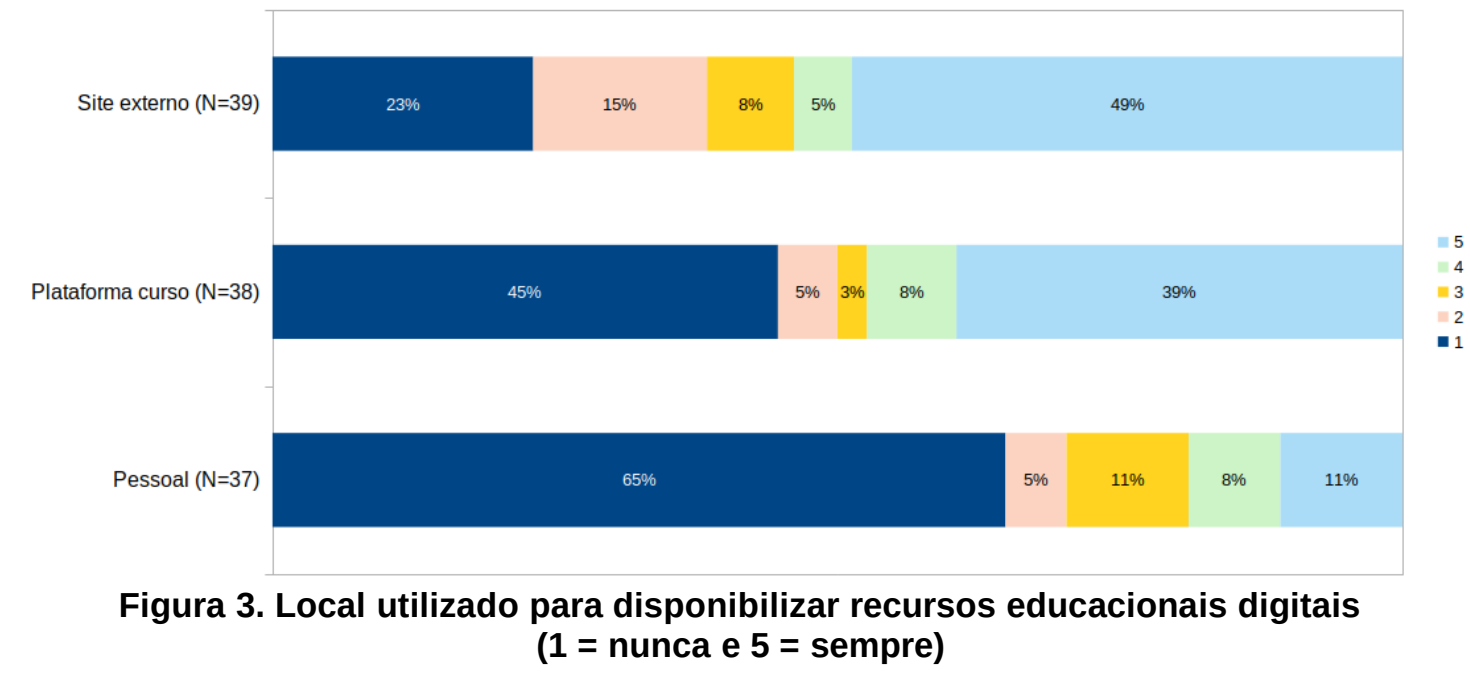


VIII Congresso Brasileiro de Informática na Educação (CBIE 2019)

Anais do XXV Workshop de Informática na Escola (WIE 2019)

O depósito de recursos educacionais em plataformas institucionais (Moodle, por exemplo) é significativo, beneficiando apenas a estudantes matriculados em suas disciplinas, e pertencentes a determinada instituição. Há pouco uso de sítios ou repositórios pessoais.

Consultados sobre a preferência dos locais de busca por recursos educacionais a prática mais comum é a feita através de buscadores online (como Google). Seguem a busca em repositório institucional (por exemplo, Biblioteca) e sites específicos online (como Portal do Professor ou YouTube). A busca em sítios de outros professores é menos comum.

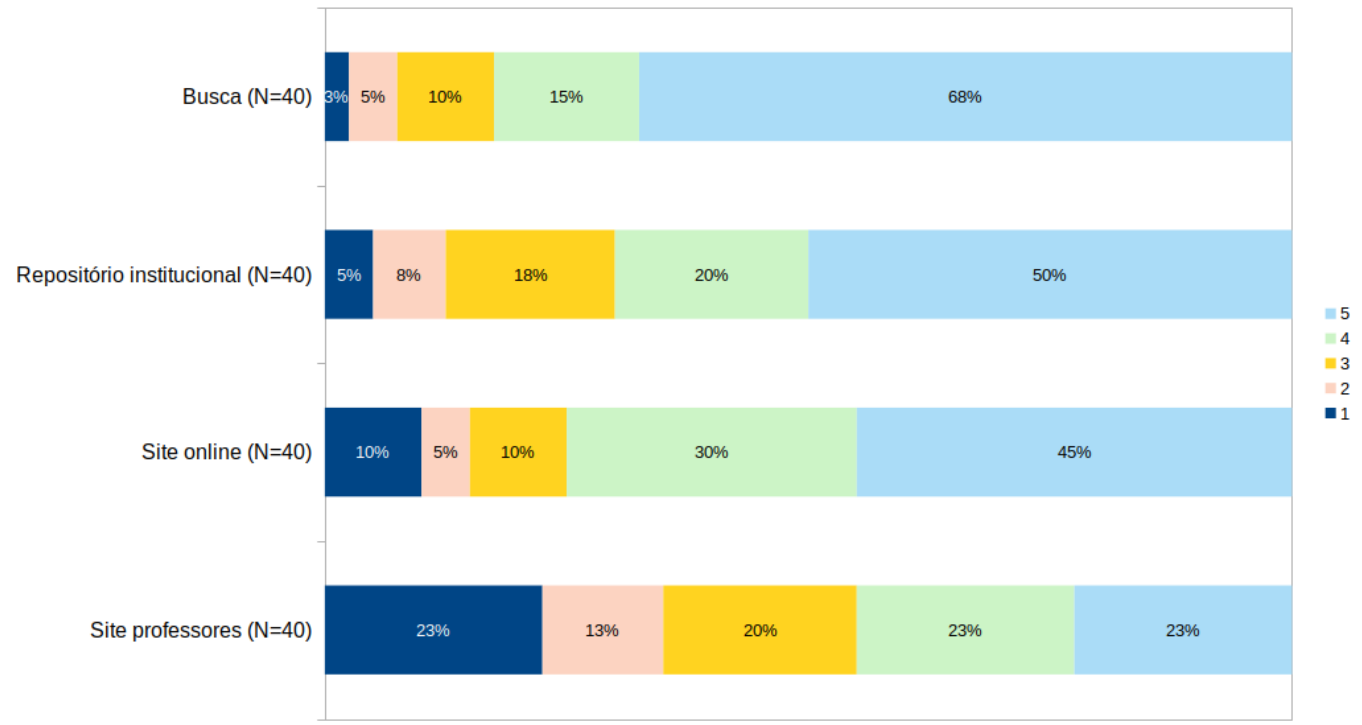

Figura 4. Local utilizado para a busca de recursos educacionais $(1=$ nunca e $5=$ sempre $)$

Perguntados sobre ações de produção de recursos educacionais (Figura 5), os docentes indicam a forte prática de produção de recursos novos e adaptação de seus próprios recursos.

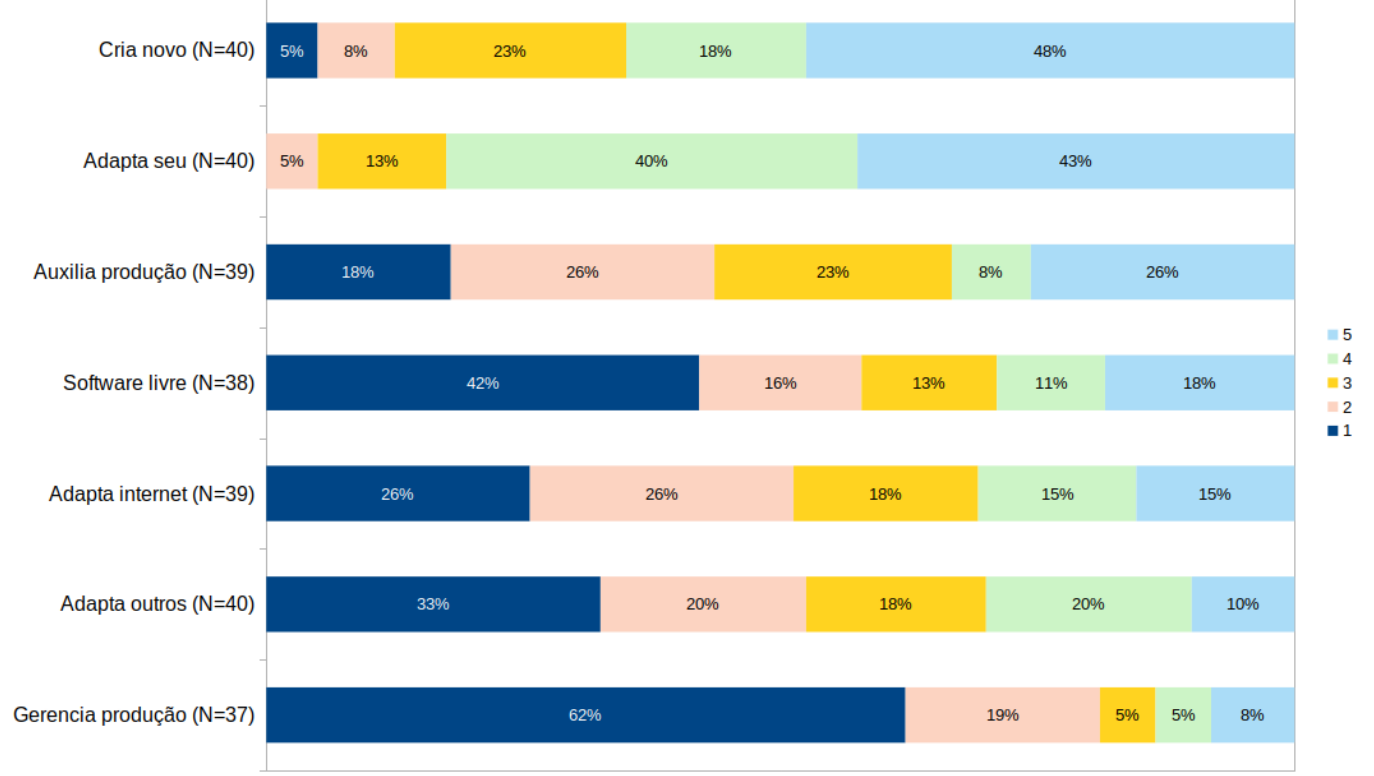

Figura 5. Produção de recursos educacionais

(1 = nunca e $5=$ sempre) 
VIII Congresso Brasileiro de Informática na Educação (CBIE 2019)

Anais do XXV Workshop de Informática na Escola (WIE 2019)

As práticas de adaptação e reuso de conteúdo nas redes e de terceiros, importante para a produção colaborativa, acontece em escala muito menor.

Perguntamos aos docentes sobre diversos fatores elencados na literatura sobre os possíveis bloqueios para o uso de recursos de terceiros (Figura 6). A preferência pelos próprios recursos, por conta da familiaridade e exclusividade para muito relevante. Há receio de alterar recursos de terceiros, relacionados também a um receio com alteração dos recursos de terceiros e violação de direitos, entre outros. Preocupações com relevância dos recursos, estilo, tempo e qualidade parecem não ser grandes barreiras para uso de recursos de terceiros.

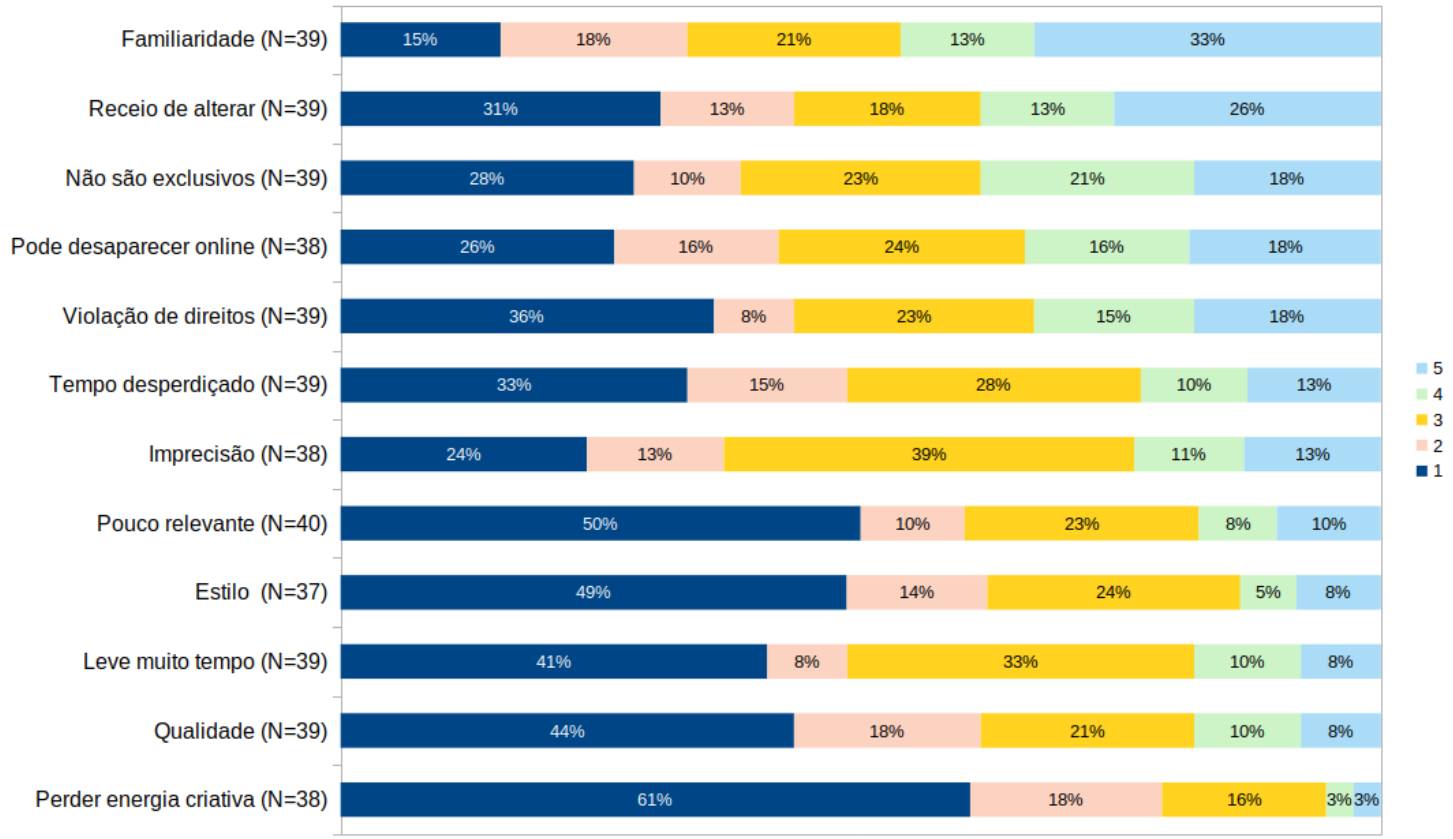

Figura 6. Bloqueios para práticas abertas (1 = pouco e 5 = muito)

Perguntamos aos docentes sobre suas preferências na seleção de recursos educacionais (Figura 7, abaixo) para suas disciplinas. Aqui, a disponibilidade dos recursos sem qualquer custo é fator de grande importância, sendo quase uma unanimidade (de maneira similar a Allen \& Seaman, 2014). Em sequência, foram apontadas a disponibilidade para download bem como a existência de uma licença aberta. De menor importância são a disponibilização em formato fonte (editável), e de forma associada, a disponibilização do material para adaptação.

\section{Análise e conclusões}

O questionário buscou levantar uma série de informações pertinentes para aferir as percepções e práticas de docentes sobre recursos educacionais. Buscou também informações relevantes associadas aos REA e práticas associadas.

Evidenciamos, como em outros estudos (Tiago Soares \& Amiel, 2017), um padrão (autoproclamado) de práticas que nos apontam contradições e tensões. Por um lado, os docentes parecem fazer amplo uso do espaço de portais e sítios web para disponibilizar os recursos educacionais que fazem uso em suas disciplinas. Buscam recursos online tanto em buscadores como em repositórios institucionais. Priorizam recursos grátis que possam ser baixados online. Indicam ter um nível baixo de restrição 
VIII Congresso Brasileiro de Informática na Educação (CBIE 2019)

Anais do XXV Workshop de Informática na Escola (WIE 2019)

na seleção de recursos de terceiros por conta de receio quanto à qualidade, estilo ou quantidade de tempo necessária para adaptação desses recursos.

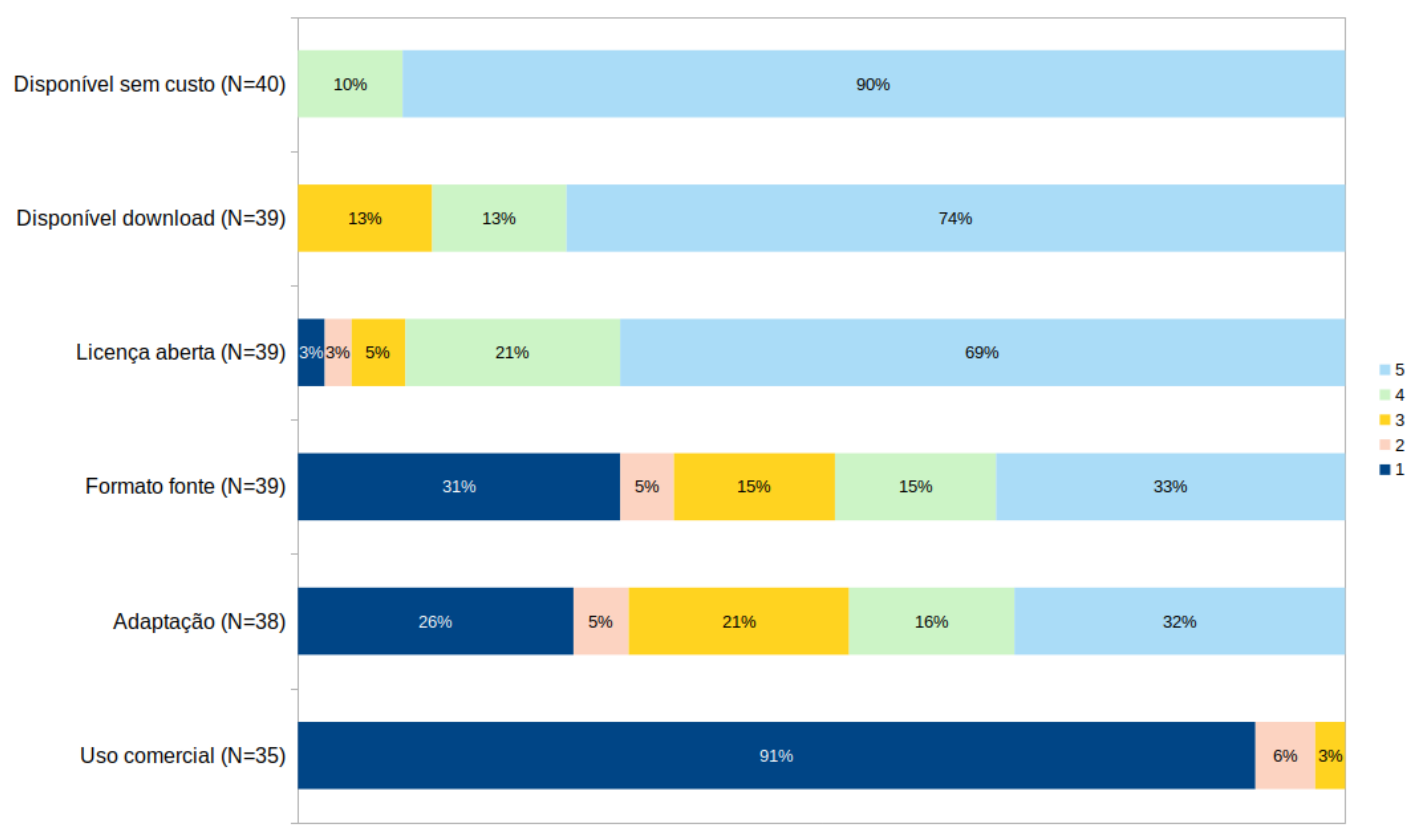

Figura 7. Prioridades na escolha de recursos (1 = pouca e 5 = muita)

No entanto, demonstram uma preferência pela produção própria, pelo que é familiar, reutilizando preferencialmente recursos criados por eles mesmos. Apontam efetivamente, um nível reduzido de práticas recombinantes, como a adaptação de recursos de terceiros e disponíveis na internet. A possibilidade de adaptação de recursos, não é um fator de grande importância na seleção dos mesmos. Os receios, são em grande parte, de ordem prática - a possibilidade de que os recursos não estejam mais online (efemeridade); o receio de adaptar os recursos de terceiros, inclusive com relação a violação de direitos autorais. Outros no entanto, são de ordem conceitual, como a qualidade da 'exclusividade' dos recursos educacionais. Santos-Hermosa (2014) indica em seu estudo que os itens mais importantes para os respondentes (em inglês) foram materiais desatualizados ou de baixa acurácia, e materiais de baixa qualidade. No mesmo estudo, a exclusividade, apontada como item importante aqui, foi considerada pouco importante (respondentes em inglês e espanhol).

As limitações quanto às competências instrumentais mais associadas à cultura digital (produção de vídeo, edição de áudio ou foto, edição de páginas colaborativas) e a baixa utilização de sítios pessoais para divulgação de material podem indicar um nível de engajamento de nível técnico maior. É importante o aprofundamento da questão, visando compreender se os sítios externos utilizados para compartilhamento são abertos, e se são espaços colaborativos de produção de conteúdo, por exemplo. O compartilhamento em ambientes fechados ou de simples disposição de conteúdo para download pode limitar a exposição dos docentes à práticas e ambientes onde a produção de conhecimento de forma aberta e livre efetivamente acontece. $\mathrm{O}$ não engajamento, limita o acesso livre ao conhecimento e não estimula a produção de REA e a remixagem de materiais educacionais.

A contradição (positiva) evidenciada no estudo se dá no sentido de que parece 
VIII Congresso Brasileiro de Informática na Educação (CBIE 2019)

Anais do XXV Workshop de Informática na Escola (WIE 2019)

haver um interesse bem como poucas barreiras atitudinais para um efetivo engajamento em práticas mais abertas e colaborativas. O processo não é simples e não acontece de forma espontânea. Como atestam Nascimbeni e Burgos (2016, p. 10):
A introdução de práticas abertas na educação faz emergir outro conjunto de tensões em maior profundidade, que têm a ver com uma mudança cultural nas atitudes e autopercepção dos educadores, relacionada com a necessidade de repensar e redimensionar os papéis desempenhados por professores e alunos nos processos de aprendizagem e no processo de construção de conhecimento subjacente, trabalhando em um ambiente aberto e transparente onde as implicações tradicionais relacionadas ao design, entrega e avaliação da aprendizagem são questionadas (tradução nossa).

Dado que um dos objetivos desse projeto foi o de levantar informações para futuras oficinas com docentes, encontramos aqui insumos para pensar em processos formativos que possam catalisar uma mudança cultura, reduzindo alguns dos anseios (como a violação de direitos autorais) e apresentem espaços e práticas colaborativas.

Os resultados não nos permitem afirmar, de fato, quais são as práticas dos docentes em sala de aula, já que se tratam de dado reportados pelos próprios docentes. É sempre possível que exista um viés que aumente a pontuação autorrelatada sobre práticas consideradas mais 'modernas' ou 'apropriadas'. No entanto, considerando os achados de estudos prévios, identificamos poucos desvios significativos no relato dos docentes.

Vemos esse questionário como uma etapa em um processo formativo - um levantamento de informações pertinentes para ações de apoio e formação. Com base nos dados, já iniciamos pequenos ciclos de formação com docentes, como por exemplo, na produção de vídeos instrucionais publicados em plataformas abertas. Futuros estudos podem usar os dados agregados do questionário para uma discussão com docentes sobre suas práticas, preferências e possibilidades, bem como um depuramento dos dados levantados, dadas as limitações inerentes a esse método de coleta de dados.

Em consonância com outros estudos mencionados, os resultados fortalecem os achados que indicam o crescente engajamento de docentes com o espaço digital, porém ainda de forma tímida quanto à colaboração, adaptação, remix e reuso. Não se trata de mera formalidade - essas práticas abrem novos dilemas e campos de discussão sobre autoria, plágio, colaboração, privacidade, direitos e outros temas que serão de suma importância para os futuros educadores. Se mostra interessante e frutífera a discussão desses desenvolvimentos a partir dos REA e das práticas abertas.

\section{Referências}

Allen, I. E., \& Seaman, J. (2014). Opening the Curriculum: Open Educational Resources in US Higher Education, 2014. Babson Survey Research Group. Retrieved from https://eric.ed.gov/?id=ED572730

Amiel, T., \& Duran, M. R. da C. (2015). Desafios do trabalho com recursos educacionais abertos na formação inicial docente. Revista EmRede, 2(2), 76-92.

Amiel, T., Gonsales, P., \& Sebriam, D. (2018). Recursos Educacionais Abertos no Brasil: 10 anos de ativismo. EmRede, 5(2), 246-258.

Bagetti, S., Mussoi, E. M., \& Mallmann, E. M. (2017). Fluência tecnológico- 
VIII Congresso Brasileiro de Informática na Educação (CBIE 2019)

Anais do XXV Workshop de Informática na Escola (WIE 2019)

pedagógica na produção de Recursos Educacionais Abertos (REA). Texto Livre: Linguagem e Tecnologia, 10(2), 185-205.

Craveiro, G., Machado, J., \& Ortellado, P. (Eds.). (2008). O mercado de livros técnicos e científicos no Brasil: Subsídio público e acesso ao conhecimento. Retrieved from http://www.forum-global.de/jm/2008-2009/Relatorio\%20Livrosportugues.pdf

de Almeida Pereira, A. M., \& Alves, T. P. (2015). Recursos educacionais abertos: Produção, compartilhamento e restrição. Hipertextus, 13, 7-25.

Fettermann, J. V. (2014). Recursos educacionais abertos na formação do professorautor: Reflexões teóricas. LINKSCIENCEPLACE - Revista Científica Interdisciplinar, 1(2), 10-17.

Mallmann, E. M., Jacques, J. S., Mazzardo, M. D., Bagetti, S., \& Lauermann, R. A. C. (2018). Autoria e coautoria como atos éticos e estéticos emergentes no movimento recursos educacionais abertos. EmRede-Revista de Educação a Distância, 5(1), 167-182.

Mazzardo, M. D., Nobre, A., \& Mallmann, E. M. (2016a). Como aprender com recursos educacionais abertos? VII Congresso de Estilos de Aprendizagem. Retrieved from https://repositorioaberto.uab.pt/bitstream/10400.2/6902/1/Como \%20Aprender\%20com\%20Recursos\%20Educacionais\%20Abertos_.pdf

Mazzardo, M. D., Nobre, A., \& Mallmann, E. M. (2016b). Small Open Online Course com Professores do Ensino Médio: Desafios para integrar REA nos materiais e atividades didáticas. Anais Do Workshop de Informática Na Escola, 22, 669. Retrieved from http://www.br-ie.org/pub/index.php/wie/article/view/6874

Nascimbeni, F., \& Burgos, D. (2016). In Search for the Open Educator: Proposal of a Definition and a Framework to Increase Openness Adoption Among University Educators. The International Review of Research in Open and Distributed Learning, 17(6). https://doi.org/10.19173/irrodl.v17i6.2736

Rodés, V., Casas, A. P., Ochoa, X., \& da Silveira, I. F. (2012). Percepciones, actitudes y prácticas respecto a los libros de texto, digitales y en formatos abiertos por parte de estudiantes de universidades de América Latina. Anais Dos Workshops Do Congresso Brasileiro de Informática Na Educação, 1.

Santos-Hermosa, G. (2014). ORIOLE, in the Search for Evidence of OER in Teaching. Experiences in the Use, Re-use and the Sharing and Influence of Repositories. Qualitative Research in Education, 3(2), 232-268.

Soares, Thiago, \& Amiel, T. (2018). A abertura e seus descontentes: Desafios na adoção de arquiteturas de educação aberta no Brasil. Proceedings of the XIII Latin-American Conference on Learning Technologies. Presented at the LACLO, São Paulo. Retrieved from http://cleilaclo2018.mackenzie.br

Soares, Tiago, \& Amiel, T. (2017). Recursos educacionais na Universidade Aberta do Brasil: Perspectivas e práticas. https://doi.org/10.5281/zenodo.1065516

Zancanaro, A., \& Amiel, T. (2017). The academic production on open educational resources in Portuguese. Revista Iberoamericana de Educación a Distancia, 20(1). https://doi.org/10.5944/ried.20.1.16332 